\title{
Pearls \& Oy-sters: A 32-Year-Old Woman With Recurrent Weakness and Paresthesias
}

Jonah P. Zuflacht, MD, and Aimee K. Boegle, MD, PhD

Neurology ${ }^{\circledR}$ 2021;97:e1537-e1540. doi:10.1212/WNL.0000000000012278
Correspondence

Dr. Zuflacht

jzuflach@bidmc.harvard.edu

\section{Pearls}

- Chronic inflammatory demyelinating polyradiculoneuropathy (CIDP) may present acutely, mimicking Guillain-Barré syndrome (GBS).

- Marked thickening and enhancement of both the cranial nerves and cauda equina roots can occur in patients with CIDP.

- Communicating hydrocephalus is an uncommon radiologic finding in patients with CIDP.

\section{Oy-sters}

- Acellular CSF is uncommon in patients with acute inflammatory myelitis and should prompt consideration of alternative diagnoses.

- Hyperreflexia does not exclude the possibility of an acute-onset inflammatory demyelinating polyradiculoneuropathy.

- Xanthochromia, though classically associated with subarachnoid hemorrhage, can be seen in patients with markedly elevated CSF protein from CIDP.

A 32-year-old woman presented with rapidly progressive quadriparesis and distal paresthesias. She had sustained a mechanical fall while walking her dog roughly 24 hours prior to presentation. Hours later, she noticed paresthesias in her feet. The next morning, she had similar tingling and numbness in her hands as well as difficulty getting out of bed. She felt unsteady when walking. She had several episodes of diarrhea but no bowel or bladder incontinence. Her symptoms progressed rapidly over the course of the day and she was soon unable to stand without assistance.

On initial evaluation, there was diffuse weakness in the bilateral deltoids, triceps, wrist extensors, finger extensors, iliopsoas, and tibialis anterior. There were no objective sensory deficits and no cranial nerve abnormalities although her speech was slightly dysarthric. Reflexes were brisk throughout with crossed adductors. The plantar response was flexor bilaterally.

MRI of the spine with and without contrast, although motion-degraded, was unremarkable. The CSF was acellular with a total protein of $295 \mathrm{mg} / \mathrm{dL}$ and glucose of $62 \mathrm{mg} / \mathrm{dL}$. Given the acuity of presentation and hyperreflexia, the patient was started on methylprednisolone for presumed transverse myelitis. Repeat MRI of the cervical spine confirmed no spinal cord signal abnormalities or pathologic enhancement and steroids were discontinued. She was started on IV immunoglobulin (IVIg) for presumed GBS and completed a 5-day course. Serum GQ1B and antiganglioside antibody testing were both negative.

Subsequent EMG and nerve conduction studies (NCS) showed markedly prolonged distal latencies, severely slowed conduction velocities, and moderately decreased response amplitudes in both arms. F-waves were absent. Motor responses of the bilateral deep peroneal, left common peroneal, and left tibial nerves were absent. Sensory responses of the left median, ulnar, and radial nerves were also absent. Together, these electrophysiologic findings supported 


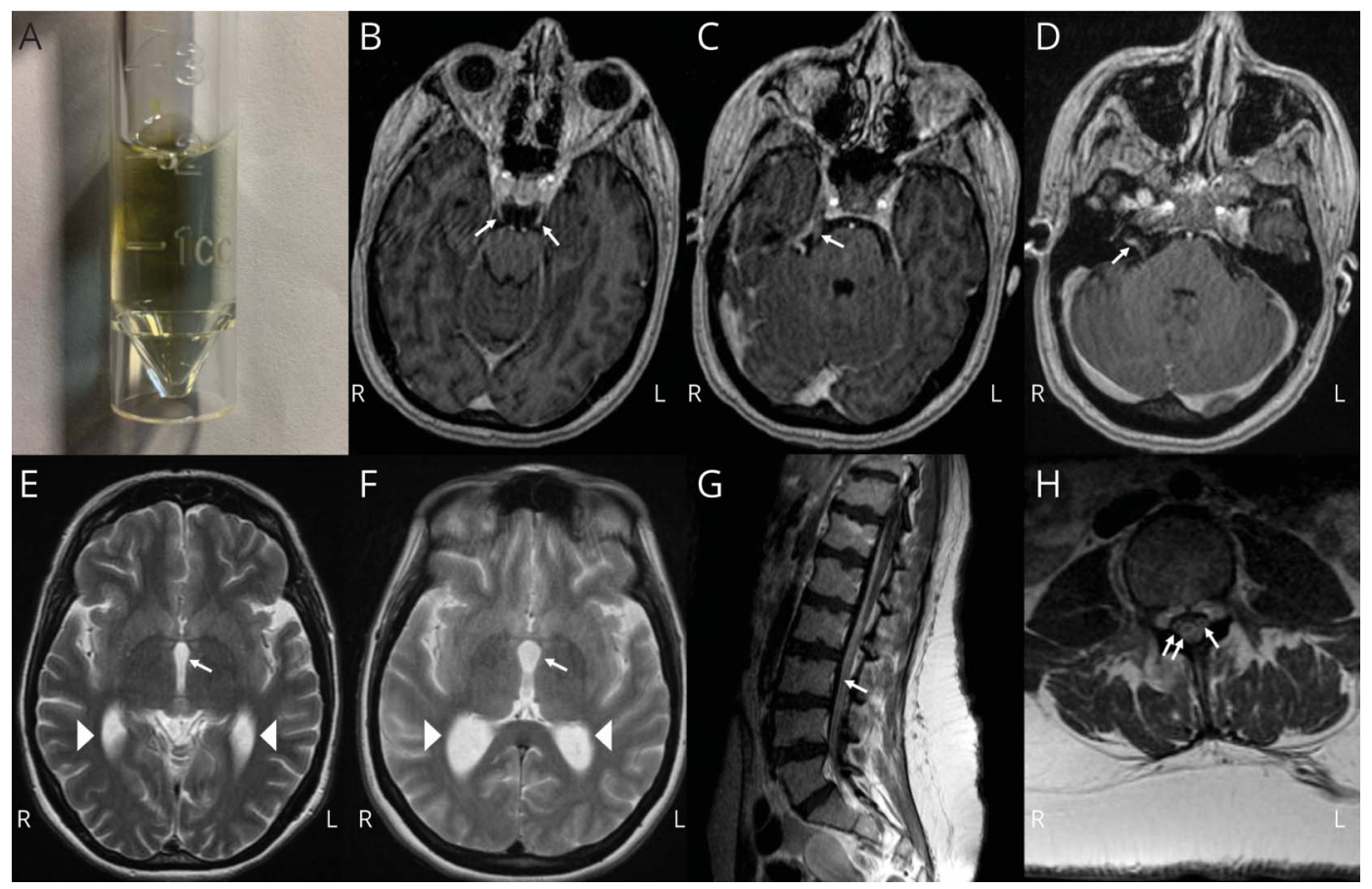

(A) CSF xanthochromia associated with markedly elevated CSF protein $(960 \mathrm{mg} / \mathrm{dL})$. Magnetization-prepared rapid acquisition with gradient echo MRI sequences of the brain with contrast at the time of relapse show thickening and enhancement of the bilateral third (B, arrows), right fifth (C, arrow), and right eighth ( $D$, arrow) cranial nerves. Interval development of mild hydrocephalus (F) at the time of relapse was compared to the initial presentation (E) as evidenced by enlargement of the third (arrows) and lateral ventricles (arrowheads) on T2-weighted MRI brain. MRI spine with contrast shows cauda equina nerve root enhancement in the sagittal $(\mathrm{G})$ and axial ( $\mathrm{H}$, arrows) planes.

the diagnosis of a severe, generalized sensorimotor polyneuropathy with primary demyelinating and secondary axonal features.

At a follow-up appointment 1 month later, the patient's strength had improved considerably; she was able to walk with a rolling walker, dress herself, and use the toilet independently. The paresthesias had also improved and her residual discomfort was well-controlled with gabapentin and pregabalin.

Four months later (6 months after her initial presentation), the patient developed recurrent, progressive weakness in her legs and arms. She also experienced worsening paresthesias in her palms and soles. On examination, there was subtle weakness in the arms and she was unable to lift her legs antigravity. Reflexes were absent throughout with the exception of the bilateral brachioradialis, which was $1+$. Repeat lumbar puncture revealed an opening pressure of $21 \mathrm{~cm} \mathrm{H}_{2} \mathrm{O}$ and xanthochromic CSF (Figure, A) with a total protein of 960 $\mathrm{mg} / \mathrm{dL}$ and glucose of $76 \mathrm{mg} / \mathrm{dL}$. There were 5 nucleated cells (91\% lymphocytes) and 1 red blood cell. Repeat MRI of the brain and spinal cord revealed extensive abnormal enhancement along the third, fifth, and eighth cranial nerves (Figure, $B, C$, and D, respectively), subtle enlargement of the ventricular system (Figure, E and F), and pronounced thickening with associated enhancement along the cauda equina nerve roots (Figure, $\mathrm{G}$ and $\mathrm{H}$ ).
Out of concern for leptomeningeal carcinomatosis, the patient underwent $\mathrm{CT}$ of the torso. This revealed bilateral breast masses considered to represent benign fibroadenomas but was otherwise unrevealing. Bilateral breast ultrasound confirmed benign breast tissue with normal axillary lymph nodes. Biopsy was deferred. CSF cytology was ultimately negative for malignant cells. Urine and protein electrophoresis revealed no monoclonal immunoglobulins. Testing for diabetes, HCV, vascular endothelial growth factor, anti-Smith antibody, antinuclear antibodies, antineutrophil cytoplasmic antibodies, rheumatoid factor, dsDNA, Sjogren antibodies, HIV, treponemal antibodies, angiotensin-converting enzyme, and paraneoplastic autoantibodies was either normal or negative.

The patient was diagnosed with relapsed acute-onset CIDP and treated with a 5-day course of IVIg followed by 3 days of highdose methylprednisolone. She was discharged to a rehabilitation facility with the plan to repeat a 5-day course of IVIg every 3-4 weeks for the next 3 months. At a follow-up appointment 3 months later, the patient had regained significant strength and was able to walk short distances without assistance.

\section{Discussion}

First described in the late 19th century, CIDP is now recognized as the most common cause of chronic autoimmune 
neuropathy. ${ }^{1}$ It is often considered the chronic form of GBS with damage to peripheral nerve myelin leading to a similar, though more insidious and often relapsing, combination of weakness, large fiber sensory loss, and areflexia. ${ }^{1,2}$ The diagnosis of CIDP can be challenging given its protean clinical manifestations and overlapping features with other peripheral nerve disorders. ${ }^{2}$ Distinguishing among CIDP, GBS, and other forms of polyneuropathy has key prognostic and treatment implications.

Most patients with CIDP will present with a gradually progressive neuropathy over the course of several months. ${ }^{1}$ At least $16 \%$ of patients with CIDP, however, will present with rapidly progressive symptoms suggestive of GBS and are only subsequently diagnosed with acute-onset CIDP (A-CIDP). ${ }^{3}$ Differentiating between A-CIDP and treatment-related fluctuations (TRF) related to GBS can be particularly difficult, especially early on. In one longitudinal study of patients with GBS and A-CIDP, patients with TRF from GBS deteriorated within the first 8 weeks of symptom onset and never had more than $2 \mathrm{TRF}^{4}$ This patient presented acutely, with weakness and sensory impairment developing over the course of 1-2 days. Given her EMG/NCS results and clinical improvement over the next few weeks, she was given the presumptive diagnosis of GBS. It was only when she deteriorated again, roughly 6 months after the initial presentation, that she was diagnosed with A-CIDP. Although nerve excitability testing may be useful in distinguishing between A-CIDP and GBS at early stages, the technique is rarely used in standard clinical practice. ${ }^{5}$

This patient was initially diagnosed with and treated for transverse myelitis. A compressive myelopathy was also considered, particularly given the antecedent fall, speed with which she deteriorated, and hyperreflexia on examination. Although initial MRI was motion degraded, it helped exclude the possibility of a structural spine lesion. Repeat MRI of the cervical spine showed no evidence of transverse myelitis and there were no cells in the CSF. While normal imaging does not exclude the possibility of a myelopathy, it is unusual for patients with an acute inflammatory myelitis to have an acellular CSF. ${ }^{6}$ Given the degree of albumin-cytologic dissociation (protein of $295 \mathrm{mg} / \mathrm{dL}$ with 0 cells), an inflammatory neuropathy (either GBS or A-CIDP) should have been considered at the outset. The presence of hyperreflexia, however, was considered to be incompatible with GBS. Indeed, areflexia or hyporeflexia is considered mandatory for the diagnosis. Yet, as noted in one recent systematic review, hyperreflexia has been observed in all variants and subtypes of GBS. $^{7}$ Antiganglioside antibodies are positive in close to $90 \%$ of patients presenting with hyperreflexia and electrophysiology studies typically reveal an axonal, rather than demyelinating, polyneuropathy. ${ }^{7}$ Interestingly, in this patient, antiganglioside antibodies were not detected and EMG/NCS revealed a generalized sensorimotor polyneuropathy with primary demyelinating features.
When the patient developed recurrent weakness 6 months after her initial presentation, neoplastic, infectious, and inflammatory etiologies of progressive polyneuropathy were considered. Repeat MRI of the brain and spine showed pronounced thickening and enhancement of both the cauda equina nerve roots as well as multiple cranial nerves. There was new hydrocephalus. Overall, these findings were believed to be suggestive of leptomeningeal carcinomatosis but an extensive workup for malignancy was ultimately negative.

In retrospect, neither of these radiologic features was incongruent with the diagnosis of CIDP. Marked hypertrophy and enhancement of both spinal and cranial nerves is commonly observed in patients with CIDP and may stem from recurrent cycles of demyelination and remyelination. ${ }^{2,8} \mathrm{Hy}-$ drocephalus, meanwhile, is rarely observed in patients with CIDP and to our knowledge has only been reported in 14 prior cases. ${ }^{9}$ The mechanism is unknown, although it has been suggested that hypertrophied spinal nerve roots can result in obstructed CSF flow. ${ }^{9}$ Protein-related blockage of the arachnoid villi is another possibility and may have played a role here. ${ }^{10}$ Elevated CSF protein is of course not unique to CIDP and can be seen in both acquired and hereditary demyelinating polyneuropathies. ${ }^{2}$ However, significantly elevated CSF protein is common in patients with CIDP and can lead to xanthochromia, as observed in our patient. $^{2}$

In this case, a unique combination of atypical clinical and radiographic features highlights why the misdiagnosis and underdiagnosis of CIDP is so frequently encountered in practice. ${ }^{2}$ Initially, the diagnosis was not considered due to the acute presentation and early hyperreflexia. Six months later, treatment was delayed out of concern for leptomeningeal carcinomatosis given diffuse nerve root thickening and enhancement with associated hydrocephalus.

\section{Study Funding}

The authors report no targeted funding.

\section{Disclosure}

The authors have no disclosures relevant to the manuscript. Go to Neurology.org/N for full disclosures.

\section{Appendix Authors}

\begin{tabular}{lll}
\hline Name & Location & Contribution \\
\hline $\begin{array}{l}\text { Jonah P. } \\
\begin{array}{l}\text { Zuflacht, } \\
\text { MD }\end{array}\end{array}$ & $\begin{array}{l}\text { Beth Israel Deaconess } \\
\text { Medical Center, Boston, }\end{array}$ & $\begin{array}{l}\text { Designed and conceptualized } \\
\text { manuscript, analyzed the data, } \\
\text { drafted the manuscript }\end{array}$ \\
\hline $\begin{array}{l}\text { Aimee K. } \\
\text { Boegle, MD, } \\
\text { PhD }\end{array}$ & $\begin{array}{l}\text { Beth Israel Deaconess } \\
\text { Medical Center, Boston, }\end{array}$ & $\begin{array}{l}\text { Interpreted the data, revised the } \\
\text { manuscript for intellectual content }\end{array}$ \\
\hline
\end{tabular}




\section{References}

1. Gwathmey K. Chronic inflammatory demyelinating polyradiculoneuropathy and its variants. Continuum. 2020;26(5):1205-1223.

2. Eftimov F, Lucke IM, Querol LA, Rajabally YA, Verhamme C. Diagnostic challenges in chronic inflammatory demyelinating polyradiculoneuropathy. Brain. 2020;143(11):3214-3224.

3. McCombe PA, Pollard JD, McLeod JG. Chronic inflammatory demyelinating polyradiculoneuropathy: a clinical and electrophysiological study of 92 cases. Brain. 1987; 110(pt 6):1617-1630.

4. Ruts L, Drenthen J, Jacobs BC, van Doorn PA; Dutch GBS Study Group. Distinguishing acute-onset CIDP from fluctuating Guillain-Barre syndrome: a prospective study. Neurology. 2010;74(21):1680-1686.

5. Sung JY, Tani J, Park SB, Kiernan MC, Lin CS. Early identification of 'acute-onset' chronic inflammatory demyelinating polyneuropathy. Brain. 2014;137(pt 8):2155-2163.
6. Jacob A, Weinshenker BG. An approach to the diagnosis of acute transverse myelitis. Semin Neurol. 2008;28(1):105-120.

7. Uncini A, Notturno F, Kuwabara S. Hyper-reflexia in Guillain-Barré syndrome: systematic review. J Neurol Neurosurg Psychiatry. 2020;91(3):278-284.

8. Kale HA, Sklar E. Magnetic resonance imaging findings in chronic inflammatory demyelinating polyneuropathy with intracranial findings and enhancing, thickened cranial and spinal nerves. Australas Radiol. 2007;51:B21-B24.

9. Iwasaki A, Kokubun N, Funakoshi K, Hirata K, Suzuki K. Hydrocephalus due to marked enlargement of spinal roots in a patient with chronic inflammatory demyelinating polyradiculoneuropathy. Eur J Neurol. 2020;27(11):2385-2388.

10. Hickman SJ, Allen JA, Baisre A, et al. Neuro-ophthalmological complications of chronic inflammatory demyelinating polyradiculoneuropathy. Neuroophthalmology. 2013;37(4):146-156. 


\section{Neurology}

\section{Pearls \& Oy-sters: A 32-Year-Old Woman With Recurrent Weakness and Paresthesias}

Jonah P. Zuflacht and Aimee K. Boegle

Neurology 2021;97;e1537-e1540 Published Online before print May 26, 2021

DOI 10.1212/WNL.0000000000012278

This information is current as of May 26, 2021

\section{Updated Information \& Services}

References

Subspecialty Collections

Permissions \& Licensing

Reprints including high resolution figures, can be found at: http://n.neurology.org/content/97/15/e1537.full

This article cites 10 articles, 2 of which you can access for free at: http://n.neurology.org/content/97/15/e1537.full\#ref-list-1

This article, along with others on similar topics, appears in the following collection(s):

All clinical neurophysiology

http://n.neurology.org/cgi/collection/all_clinical_neurophysiology Chronic inflammatory demyelinating polyneuropathy

http://n.neurology.org/cgi/collection/chronic_inflammatory_demyelinat ing_polyneuropathy

Clinical neurology examination

http://n.neurology.org/cgi/collection/clinical_neurology_examination Guillain-Barre syndrome

http://n.neurology.org/cgi/collection/guillainbarre_syndrome MRI

http://n.neurology.org/cgi/collection/mri

Information about reproducing this article in parts (figures,tables) or in its entirety can be found online at:

http://www.neurology.org/about/about_the_journal\#permissions

Information about ordering reprints can be found online:

http://n.neurology.org/subscribers/advertise

Neurology ${ }^{\circledR}$ is the official journal of the American Academy of Neurology. Published continuously since 1951, it is now a weekly with 48 issues per year. Copyright (C 2021 American Academy of Neurology. All rights reserved. Print ISSN: 0028-3878. Online ISSN: 1526-632X.

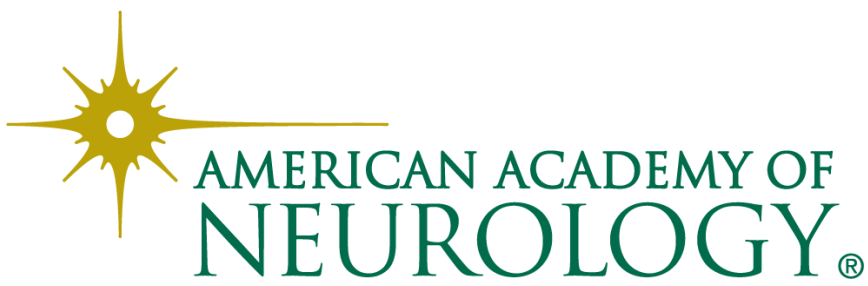

